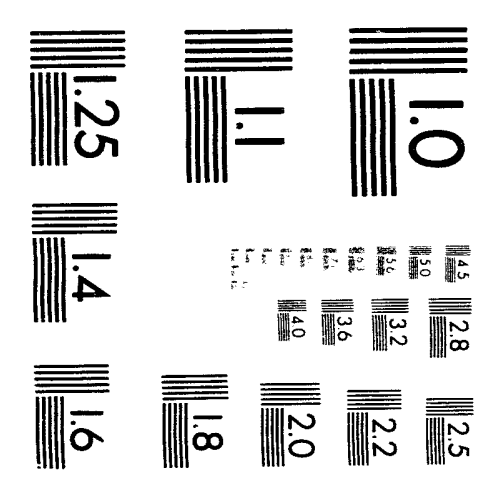



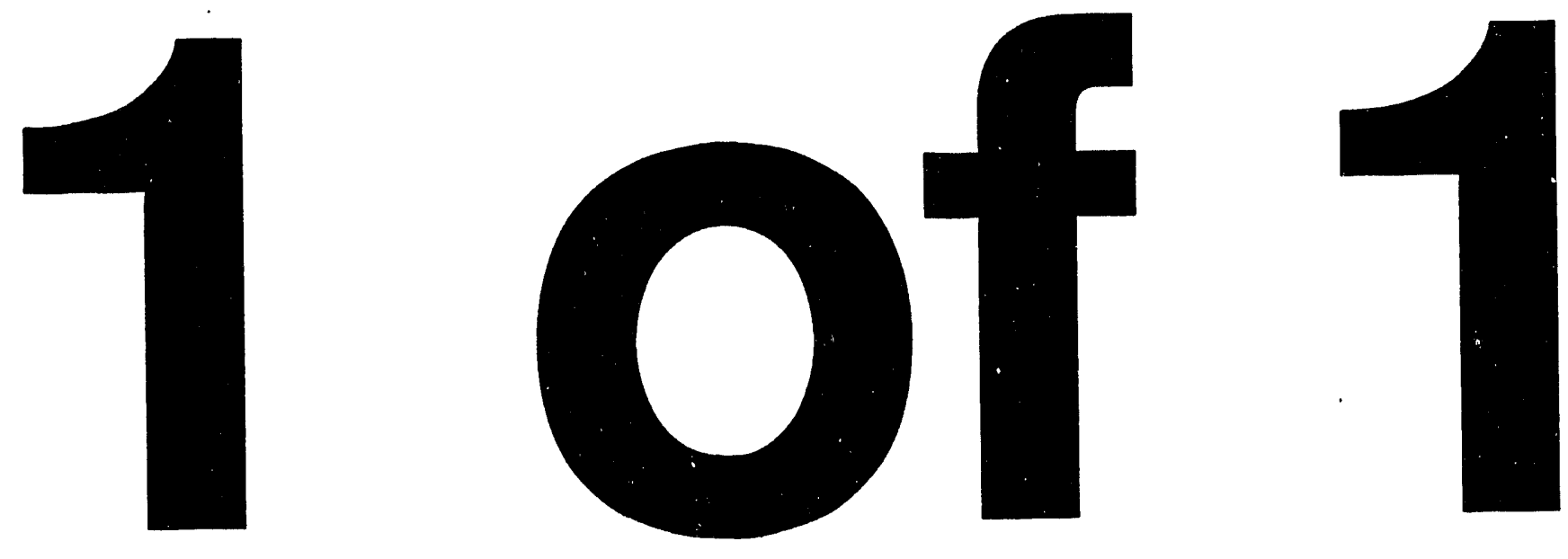


\title{
Design of a Crystal Extraction Facility in the East Utility Straight
}

\author{
E. C. Dukes \\ University of Virginia \\ Charlottesville, VA 22903 \\ C. T. Murphy \\ Fermi National Accelerator Laboratory \\ Batavia, IL 60510 \\ and \\ B. Parker \\ Superconducting Super Collider Laboratory* \\ 2550 Beckleymeade Avenue \\ Dallas, Texas 75237
}

September 1993

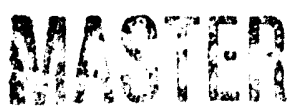

" Operated by the Universities Research Association, Inc., for the U.S. Department of Energy under Contract No. DE-AC35-89ER40486. 


\title{
Design of a Crystal Extraction Facility in the East Utility Straight
}

\author{
E. C. Dukes, C. T. Murphy, and B. Parker
}

\begin{abstract}
Parasitic extraction of a small fraction of the $20-\mathrm{TeV}$ circulating beam of the Superconducting Super Collider can be done using a bent crystal situated in the halo of the orbiting beam. We present a design of a crystal extraction system that is compatible with current plans for momentum scraping in the east utility straight. The only modification to the collider tunnel is the addition of a $160-\mathrm{m}$-long alcove in the east utility straight to mate the extracted beam line microtunnel with the collider tunnel. No other changes to the east utility straight tunnel are needed.
\end{abstract}




\subsection{INTRODUCTION}

The option of extracting a small fraction of the circulating 20-TeV Superconducting Super Collider (SSC) beam has been discussed for some time. ${ }^{1}$ The potential uses of such a beam would be many; in particular, the opportunities to do $B$-physics are very appealing and have led to an Expression of Interest (EOI-14) that discusses extracting approximately $10^{8}$ protons/s from the halo of the circulating beam using a bent silicon crystal. ${ }^{2}$ From the beginning the SSC has recognized the exciting physics potential of an extracted beam, and the SSC footprint includes a stratified-fee land area and a buried beam zone access area for the muon vector from an extracted-beam hall. ${ }^{3}$ (See Figure 1.)

The channeling of high-energy particles in bent crystals has been observed in the momentum range of $1.7-800 \mathrm{GeV} / \mathrm{c}^{4}$ Crystal channeling of charged particles has been used in high-energy physics experiments for over a decade. Examples of recent uses of crystal channeling include the measurement of the magnetic moment of the $\Sigma^{+}$hyperon. ${ }^{5}$ Future uses include a channeled proton beam for CERN $C P$-violation experiment NA48. ${ }^{6}$ Recently, the potential of crystal channeling for parasitic extraction in high-energy colliders has received much interest. Crystal extraction of proton beams has been demonstrated at Dubna and Serpukhov in the GeV range. Extraction of $120-\mathrm{GeV}$ proton beams was successfully carried out last year at CERN. ${ }^{7}$ Further tests are underway at CERN-where a $9 \%$ efficiency has recently been obtained ${ }^{8}$ - and at Fermilab. ${ }^{9}$ Crystal channeling of high-energy particles is rapidly becoming a proven experimental technique.

In this report we consider the implementation of a crystal extraction system in the east utility straight of the SSC. We show that an extraction system can be added with only minor alterations to the collider: the addition of a three-magnet dogleg (identical to that designed for the west utility straight); the addition of two dipole strings; and the addition of a 160-m-long alcove to mate the extracted beam line microtunnel to the collider tunnel. The present scheme to allow for momentum scraping in the east utility straight is not affected. The design of the alcove is similar to that of the two alcoves needed for the scraper shielding in the east utility straight. As is the case with the scraper alcoves, excavating it before the tunnel is finished is cost-effective and would alleviate much of the disruption and added cost involved in adding an alcove to the finished tunnel at a later date. 


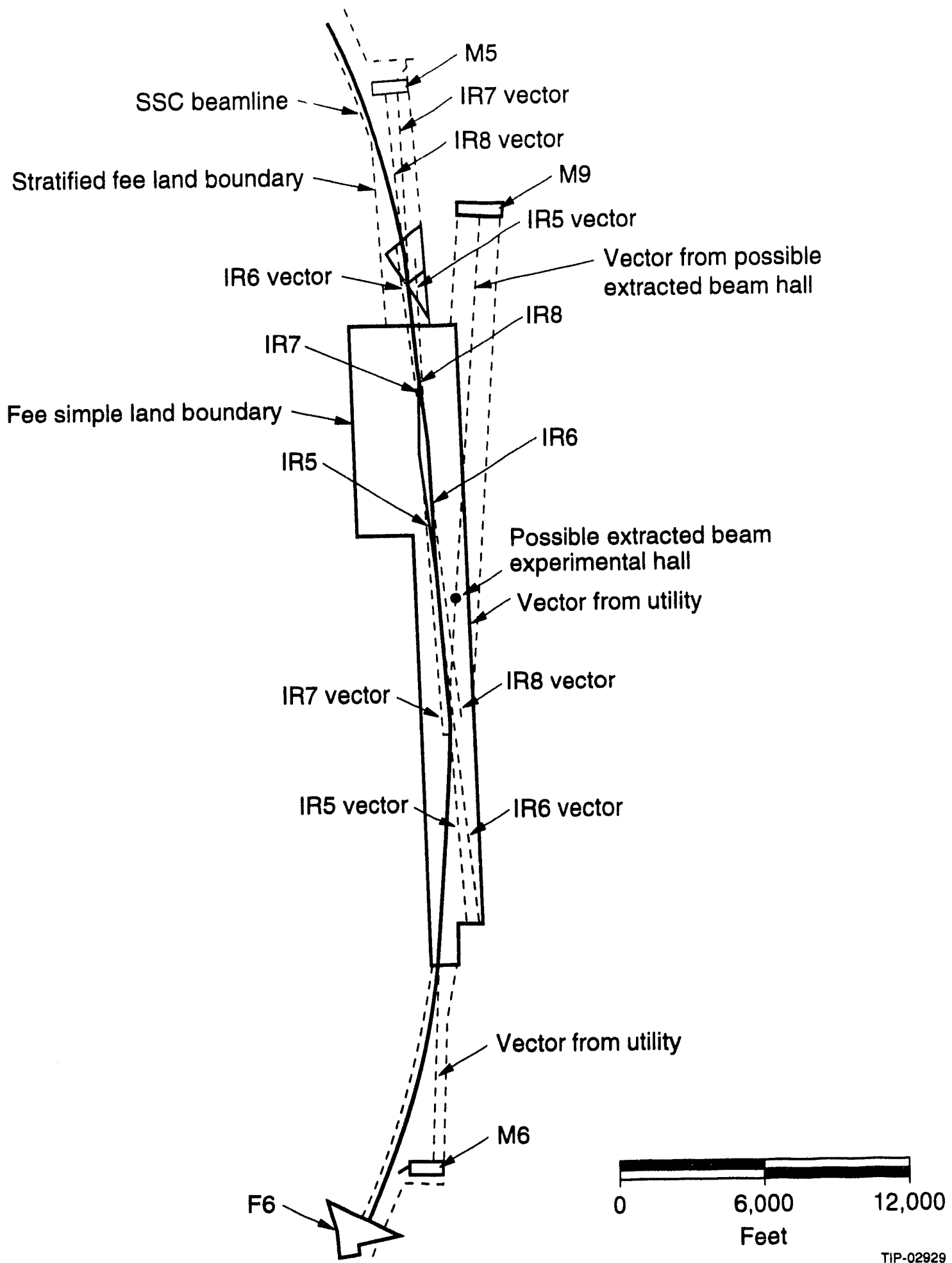

Figure 1. Footprint of the east cluster of the Superconducting Super Collider. 


\subsection{SHORT DESCRIPTION OF THE EXTRACTION SYSTEM}

The east utility straight is $1350 \mathrm{~m}$ long. It is followed (going north) by a dispersion suppressor bend (DS) of $270 \mathrm{~m}$ length, a utility transition bend (TU) of $1080 \mathrm{~m}$ length, another dispersion suppressor bend of $270 \mathrm{~m}$ length, and finally a transition straight (TI) of $180 \mathrm{~m}$ length that leads into the interaction region IR-5 (Figure 2). Details of the utility straights, including magnet and spool piece specifications, are given in Reference 10. Details of the collider are given in Reference 11.

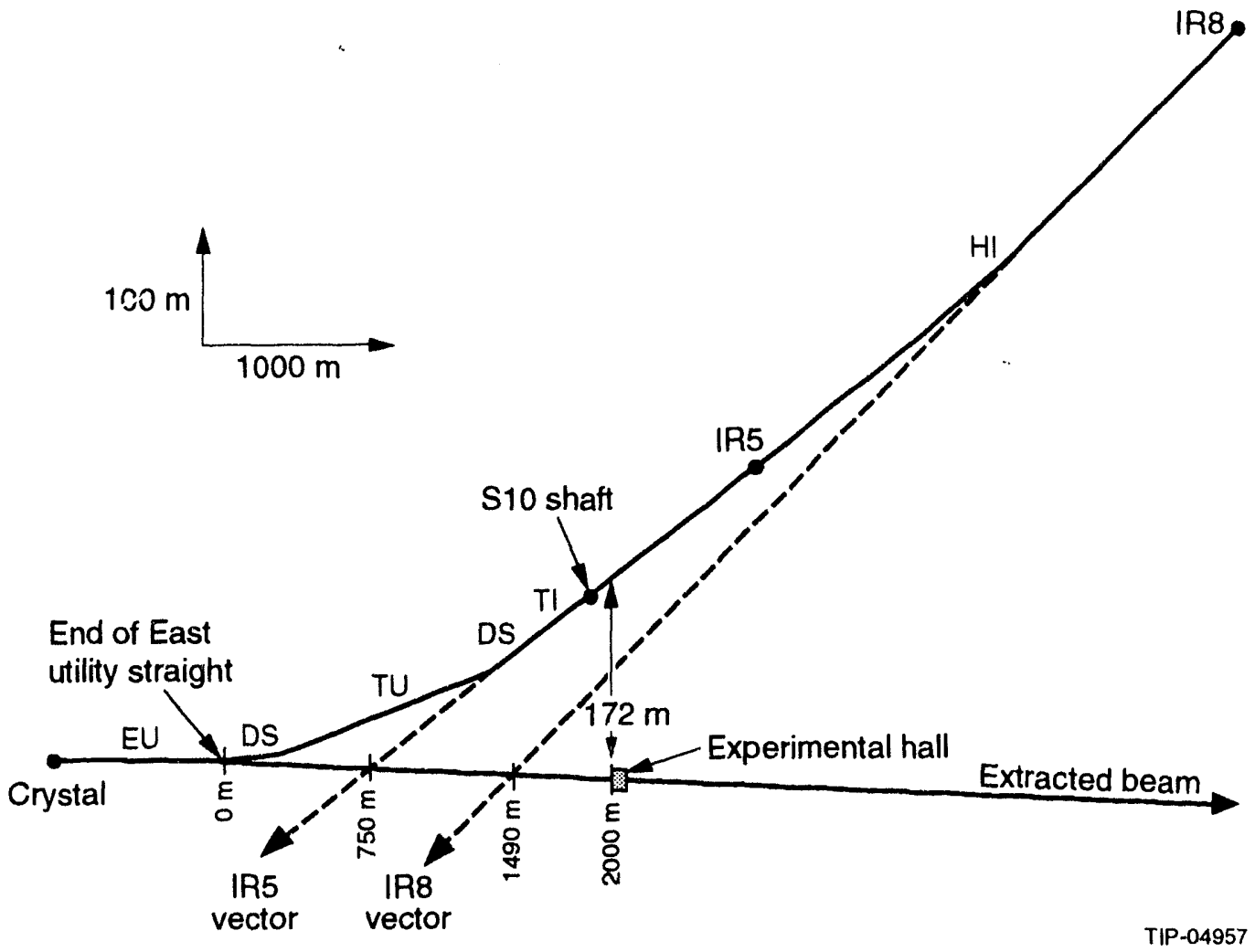

Figure 2. The extracted beam line. Shown are muon vectors from IR5 (GEM) and IR8 (SDC).

Note that many of the details of the design of the collider are not yet final. Hence some of the information here has come from private discussions with Nikolai Mokhov on the east utility scraper system, Robert Smellie on the spool pieces and magnet supports, and John Shively on the civil construction of the tunnel.

The position of magnets in the east utility straight is given in Figure 3 , where the coordinates are given relative to the beginning of the straight, which is defined throughout this document to be the center of the QS quadrupole magnet at the south end of the east utility straight. (These coordinates come from the latest version (top_rev1) of the lattice; while not yet final, they are probably good to a few meters.) Changes to the lattice to allow momentum scraping in a large dispersion region are still in progress. The dispersion needed 
for momentum scraping is consistent with that needed for crystal extraction. Momentum scraping will be done with a system of scrapers and collimators situated in a warm dogleg. The extraction scheme proposed here is consistent with the present ideas for momentum scraping in the east utility straight, although the dogleg angle required for extraction is slightly larger in order to allow the extracted beam to completely miss the spool pieces and cryostats of downstream magnets.

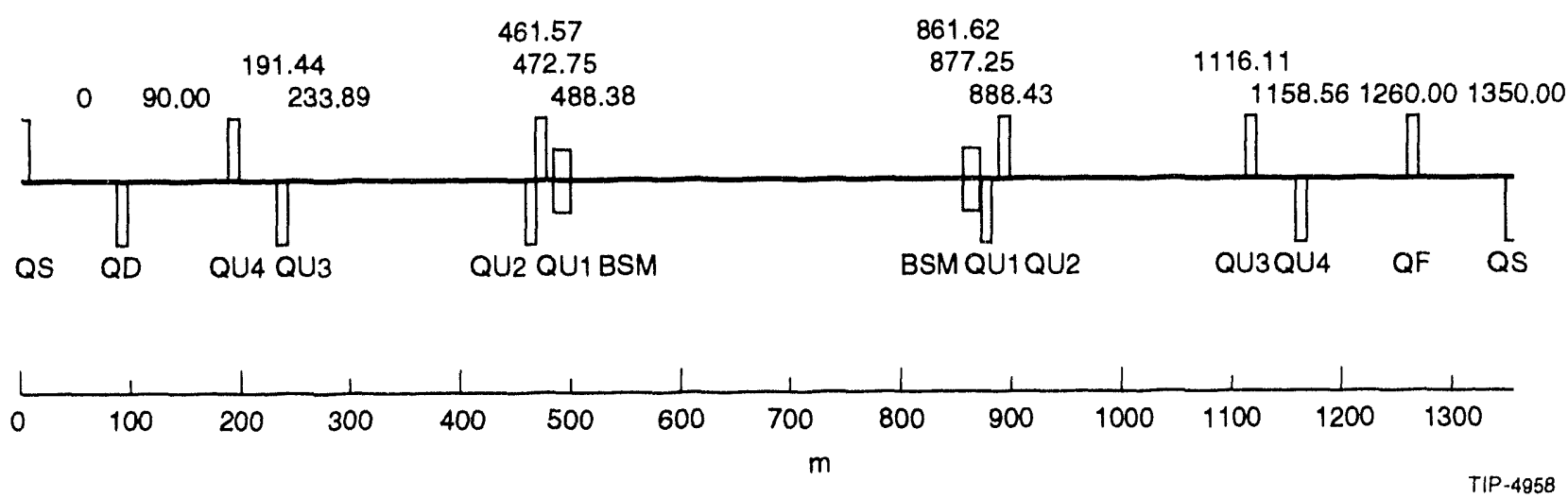

Figure 3. Coordinates of the magnets in the east utility straight. All numbers are given relative to the center of the QS quadrupole magnet at the beginning of the straight and refer to the magnet centers.

The extraction line is shown in schematic form in Figure 4. The lower circulating beam (which is headed north) is bent toward the outside of the ring by a dipole magnet. Immediately after the bend, a silicon crystal channels a small fraction of the beam halo in the vertical direction by an angle of about $160 \mu \mathrm{rad}$. The channeled particles enter the field-free region of a Lambertson magnet string and continue down the utility straight. Near the end of the dogleg a warm dipole string (ED1) steers the beam (by 0.308 mrad) into an alcove of $160 \mathrm{~m}$ length situated at the end of the east utility straight. A string of five standard collider 15-m dipole magnets (ED2) at the alcove bends the extracted beam further away (by $7.600 \mathrm{mrad}$, for a total bend of $8.555 \mathrm{mrad}$ ) from the utility straight and into a microtunnel of $18 \mathrm{in}$. diameter and $150 \mathrm{~m}$ length. Another microtunnel of 48 in. diameter follows, connecting to a 15 -ft-diameter shaft. After the two microtunnels the beam is far enough away from the collider tunnel to allow for shafts and large-diameter tunnels to be excavated without compromising the integrity of the collider tunnel. 


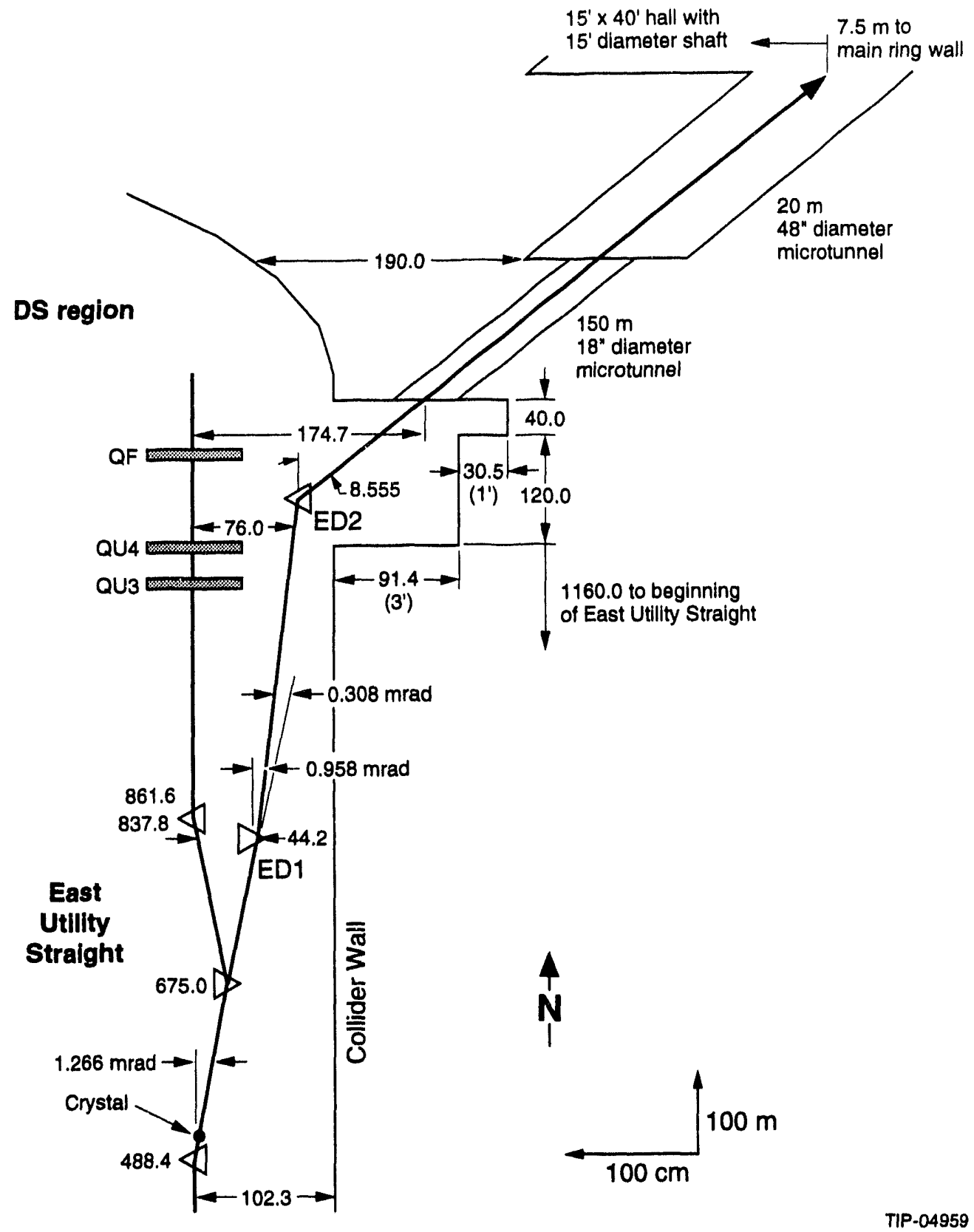

Figure 4. Plan view of the extraction line for the east utility straight showing the alcove and the microtunnel out to the first shaft. The positions of the magnetic elements are given in meters from the beginning of the east utility straight. Dimensions along the beam direction are in meters, whereas dimensions transverse to the beam direction are in centimeters. 


\subsection{DOGLEG PORTION OF THE EXTRACTION SYSTEM}

The dogleg portion of the extracted beam is shown in Figure 5. It is a direct copy of the dogleg used for the beam abort in the west utility straight (with a few elements such as the abort painters and blowup quadrupoles removed). The lower beam (which is going north) is bent $1.266 \mathrm{mrad}$ toward the outside of the tunnel (away from the center of the ring) by a 13-m BSM dipole magnet. After the BSM magnet, a 2-m insert houses the crystal and goniometer, which is moved horizontally into the halo of the circulating beam. Details of the QU2, QU1, and BSM magnet string are shown in Figure 6, which also shows the position of the crystal insert and spool pieces. The crystal is slightly bent in the vertical direction to give a bend of $160 \mu \mathrm{rad}$ upward to channeled protons (Figure 7). The channeled protons enter the field-free region of a 144-m-long Lambertson string and continue past the magnets at the end of the dogleg. At the first Lambertson the channeled beam has been displaced $14 \mathrm{~mm}$ in the vertical direction. The apex of the field-free region of the symmetric Lambertsons is $10 \mathrm{~mm}$ from the circulating beam center, so this bend should be adequate (Figure 8). Larger bends can be achieved with longer crystals (at the expense of slightly more dechanneling due to hadronic interactions in the crystal).

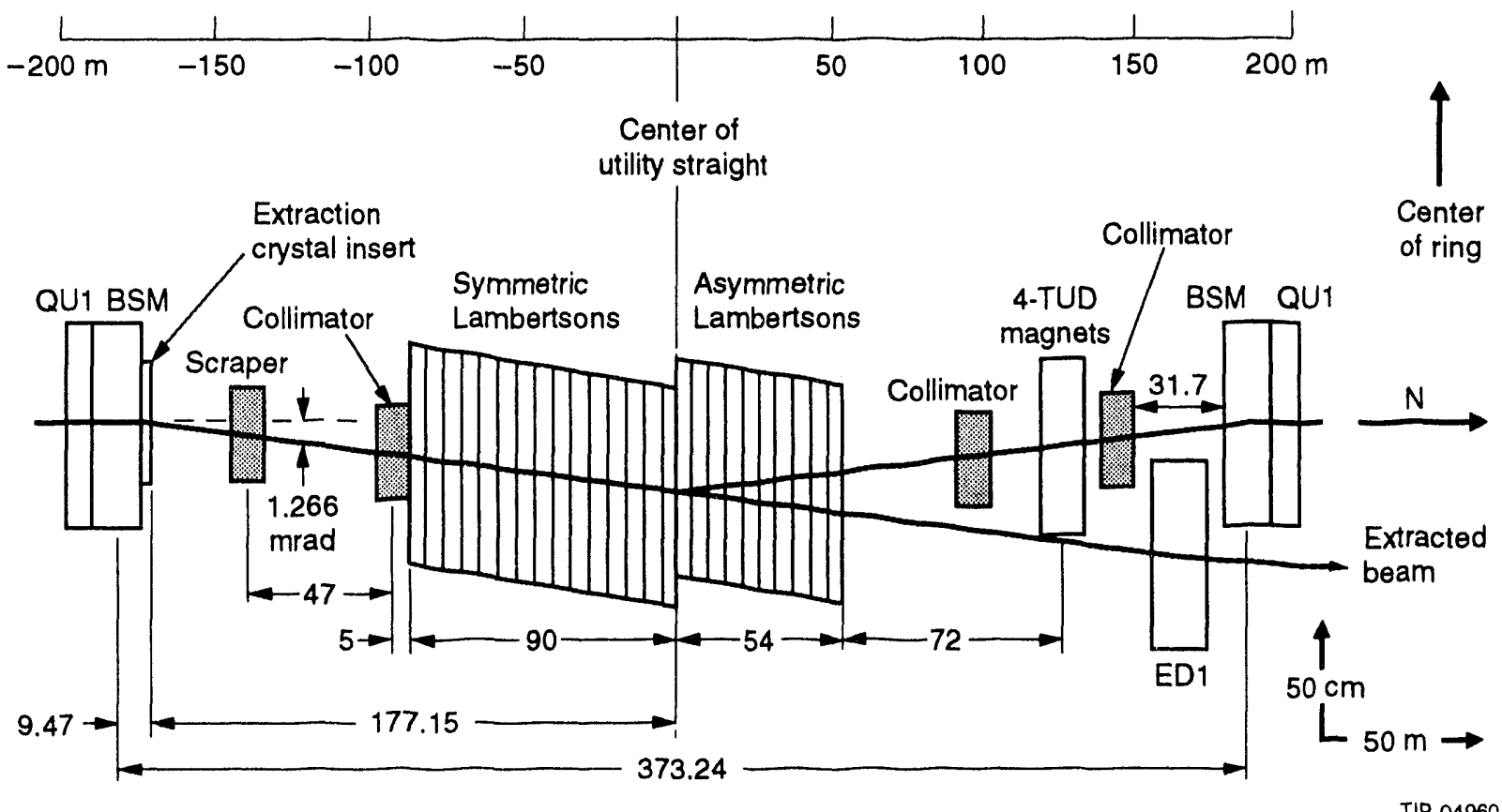

Figure 5. Plan view of the dogleg portion of the east utility extraction line. All dimensions are in meters. Note that scrapers and collimators are not to scale in the direction transverse to the beam. 


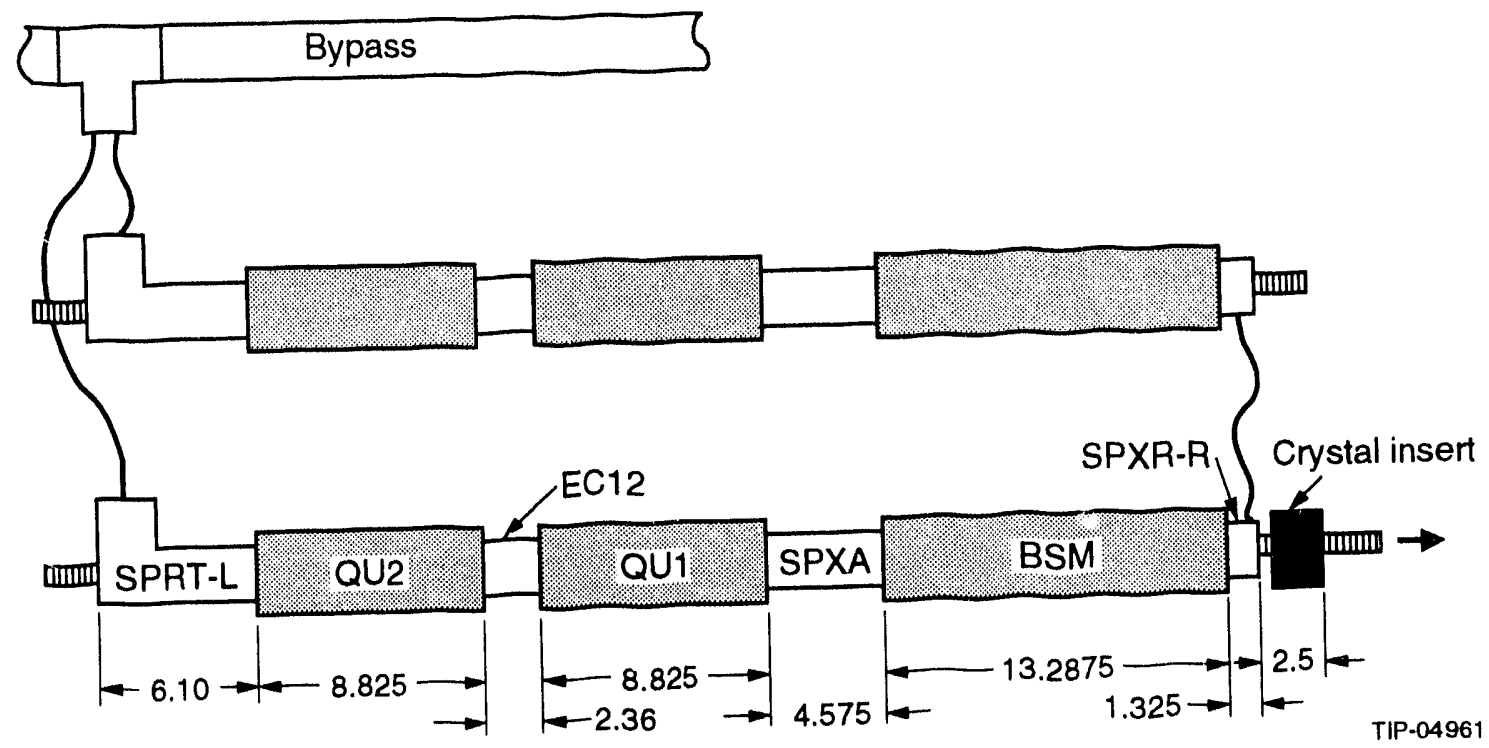

Figure 6. Detail of the BSM-QU1-QU2 magnet string and the crystal insert at the start of the dogleg. Dimensions are in meters.

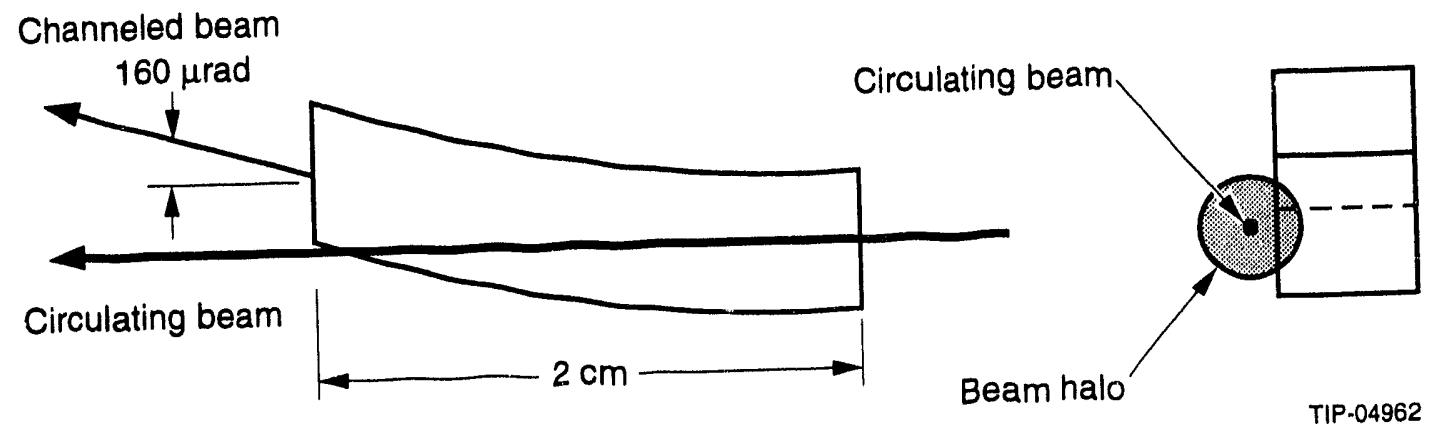

Figure 7. Bent silicon crystal in the halo of the circulating beam. The bend is grossly exaggerated.

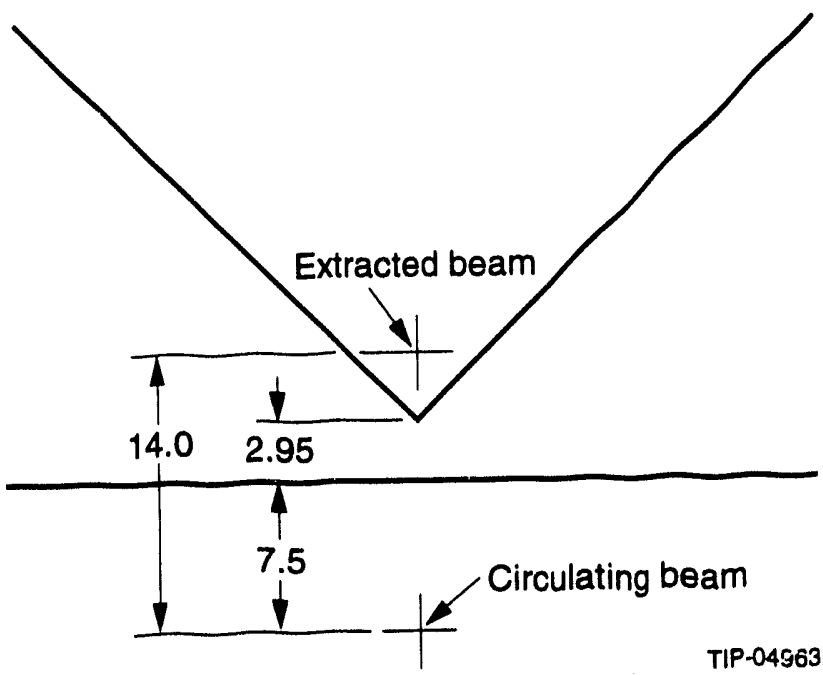

Figure 8. Position of the channeled beam at the first Lambertston. Dimensions are in millimeters. 
The positions of the scrapers and collimators in the east utility straight are consistent with the addition of the Lambertson and closed-orbit dipole magnets. Note that the lateral size of the scrapers and collimators in Figure 5 is not to scale. Also omitted is tne shielding required for the momentum scrapers and the position of the alcoves to accommodate the shielding. They are positioned at approximately $150 \pm 15 \mathrm{~m}$ from the center of the straight and are $25 \mathrm{~m}$ long.

Although the dogleg is copied from the west utility straight, care must be taken to see whether the elements fit because the east utility straight tunnel is only $14 \mathrm{ft}$ in diameter-unlike the west utility straight tunnel, which is $17 \mathrm{ft}$ in diameter. The normal positions of the beam, cryostats, and wall relative to the theoretical center of the tunnel are shown in Figure 9. Note that because of a maximum allowance of $8 \mathrm{in}$. in the center of the real tunnel relative to the theoretical center, the tunnel wall can be 8 in. closer to the beam line elements than nominal. Care has been taken to ensure that all extracted beam line elements fit, given this worst-case scenario.

Not shown in Figure 9 is the position of the cryobypass, as there is not yet a design of one for a 14-ft-diameter tunnel. A cryobypass is needed for the 14-ft-diameter tunnel near the interaction regions. It is assumed that that design can be copied. It will not be ready for several months. ${ }^{12}$

Figure 10 shows the position of the last symmetric Lambertson with respect to the tunnel cross section. At this point-the center of the dogleg-the extracted beam has been bent by $23.6 \mathrm{~cm}$ to the outside of the tunnel. The Lambertson is well within the worst-case tunnel wall position. Figure 11 shows the position of the last asymmetric Lambertson with respect to the tunnel cross section. Again, the magnet is well within the worst-case tunnel wall position.

The beam must also bypass the BSM-QU1-QU2 magnet string and spool piece elements at the end of the dogleg. The position of the beam at the first downstream elementthe BSM dipole magnet center-is shown in Figure 12. The offset of the extracted beam from the nominal beam position is $47.2 \mathrm{~cm}$. It misses the magnet cryostat with adequate clearance. Figures 13-15 show the cross sections of the SPXR-R turnaround box, the SPXA interconnect, and the SPRT-L spool pieces, respectively. In each of these figures the aisle side is to the right. The SPXA interconnect has the largest protrusion on the extracted beam side of all of the elements in the BSM-QU1-QU2 magnet string. Its cross section is given in Figure 14. The bypass gas flow valves are $41.4 \mathrm{~cm}$ from the beam line. The extracted beam at this position is $48.1 \mathrm{~cm}$ from the beam line so there is adequate clearance. Note that the design of the spool piece elements is not yet final. However, the requirements for the abort line in the west utility straight are similar to those for the 
extraction system described here; hence large protuberances on the tunnel side of the spool pieces are unlikely.

As is evident in Figure 12, the extracted beam goes through the magnet supports of the three magnets at the end of the dogleg. (A detailed drawing of the magnet support is shown in Figure 16.) If the tunnel wall is at its nominal value, or further out from the theoretical tunnel center, then a magnet support identical to that being designed for the west utility straight, where the beam abort also goes through stand magnet supports, can be used. Otherwise, a special magnet support will be needed for the three magnets at the end of the dogleg. In order to avoid the stands for the cryostats between the BSM-QU1QU2 string and the QU3 quadrupole, a warm pipe with a cryobypass will be used. (Empty cryostats have the same cross section as magnets.)

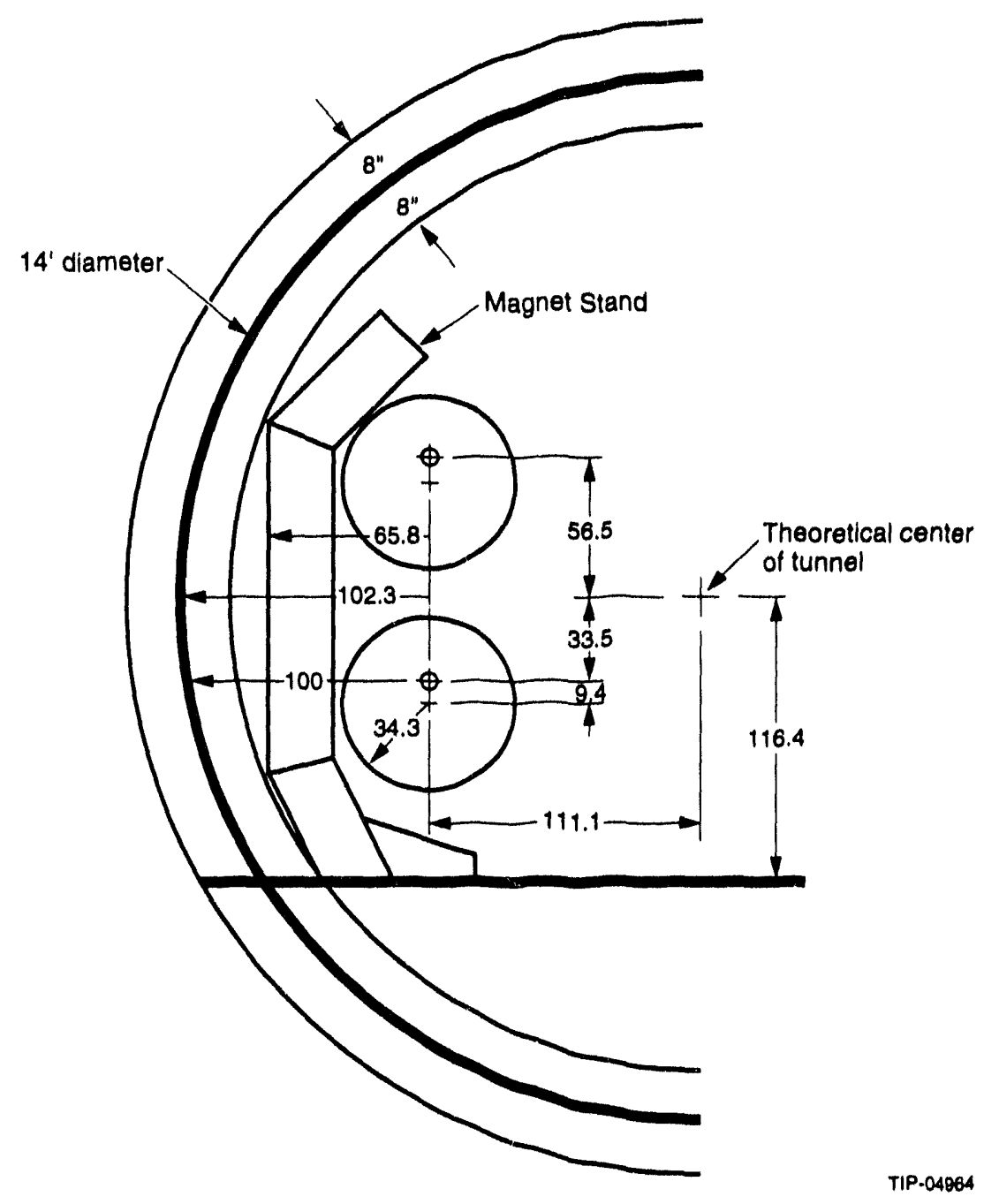

Figure 9. Normal position of the beam, cryostat, and magnet supports in the 14-ft-diameter tunnel. The nominal wall position is given as well as the maximum and minimum allowable deviations of the tunnel wall relative to the theoretical center of the tunnel. All dimensions are in centimeters unless otherwise noted. 


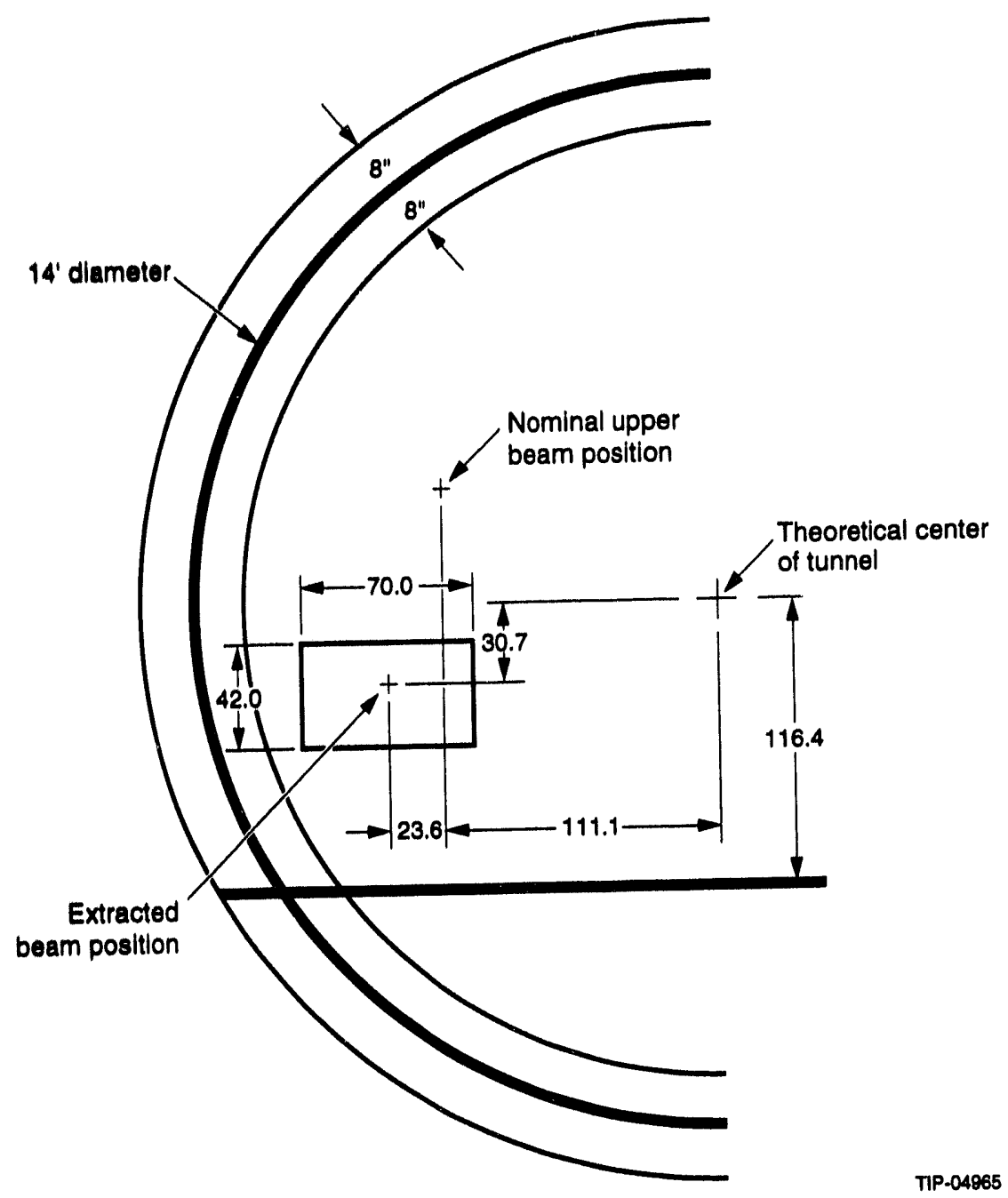

Figure 10. Cross section of the tunnel at the last symmetric Lambertson. All dimensions are in centimeters unless otherwise noted. 


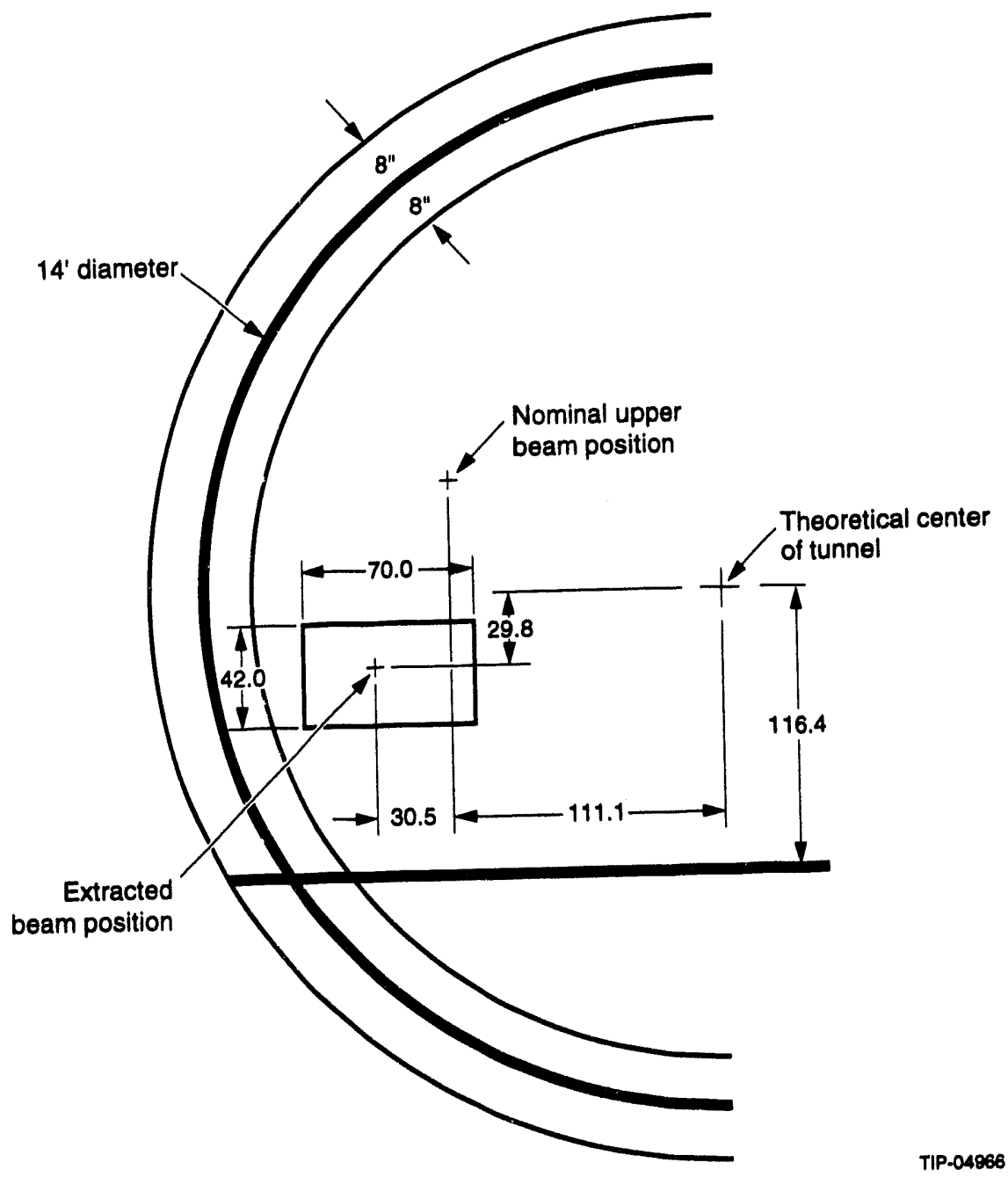

Figure 11. Cross section of the tunnel at the last asymmetric Lambertson. All dimensions are in centimeters unless otherwise noted. 


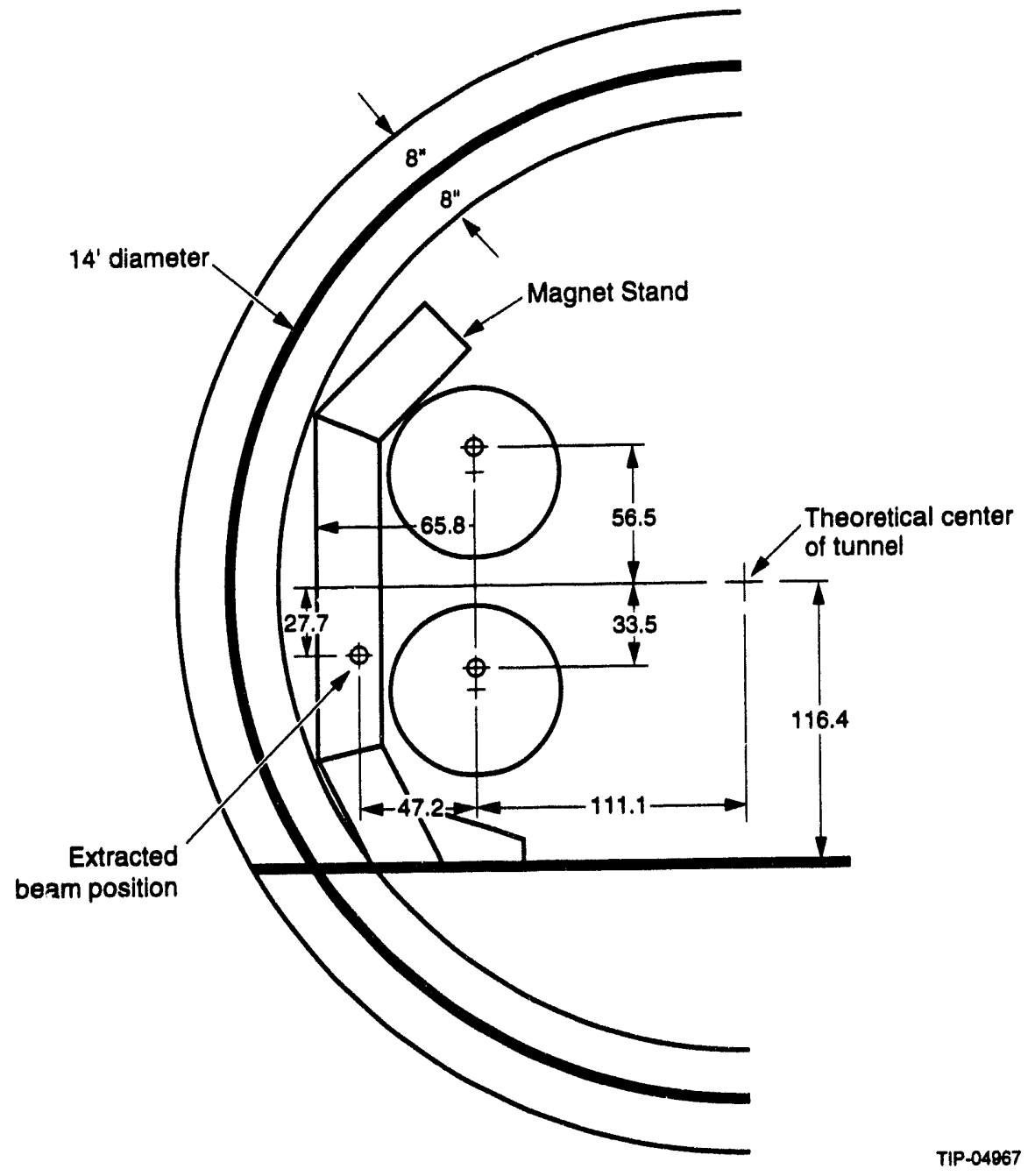

Figure 12. Cross section of the tunnel at the center of the BSM dipole magnet at the end of the dogleg ( $861.62 \mathrm{~m}$ from the beginning of the east utility straight). All dimensions are in centimeters unless otherwise noted. 


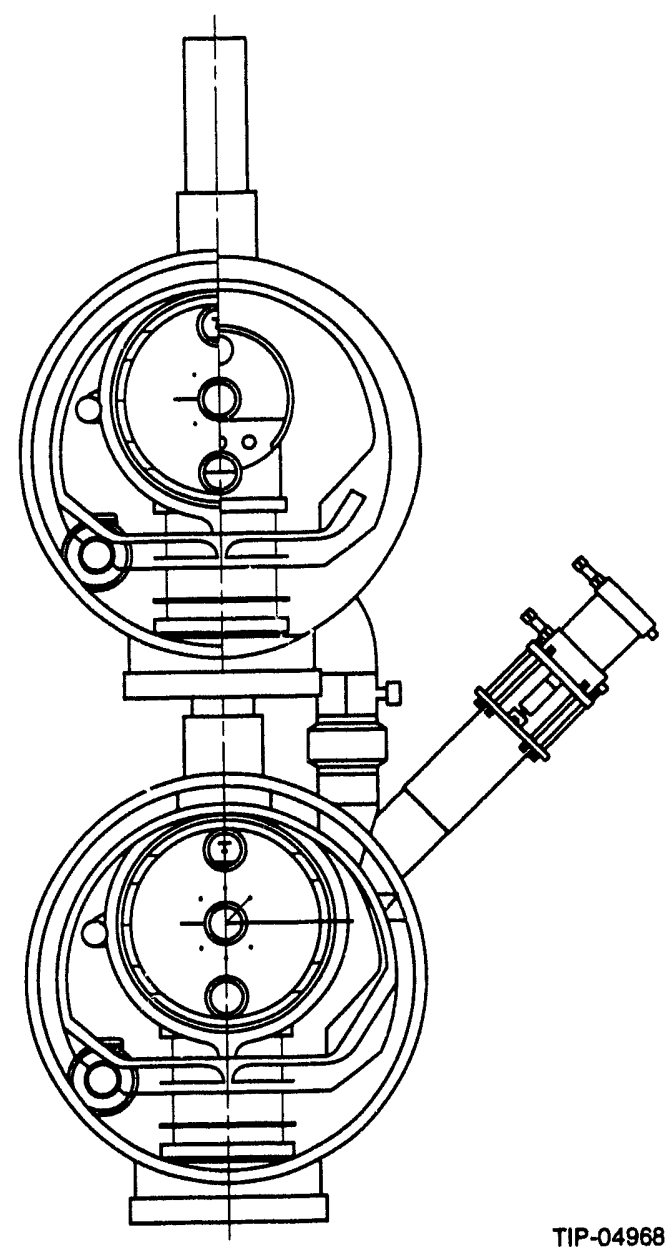

Figure 13. Cross section of the SPXR-R turnaround box. The collider aisle is to the right.

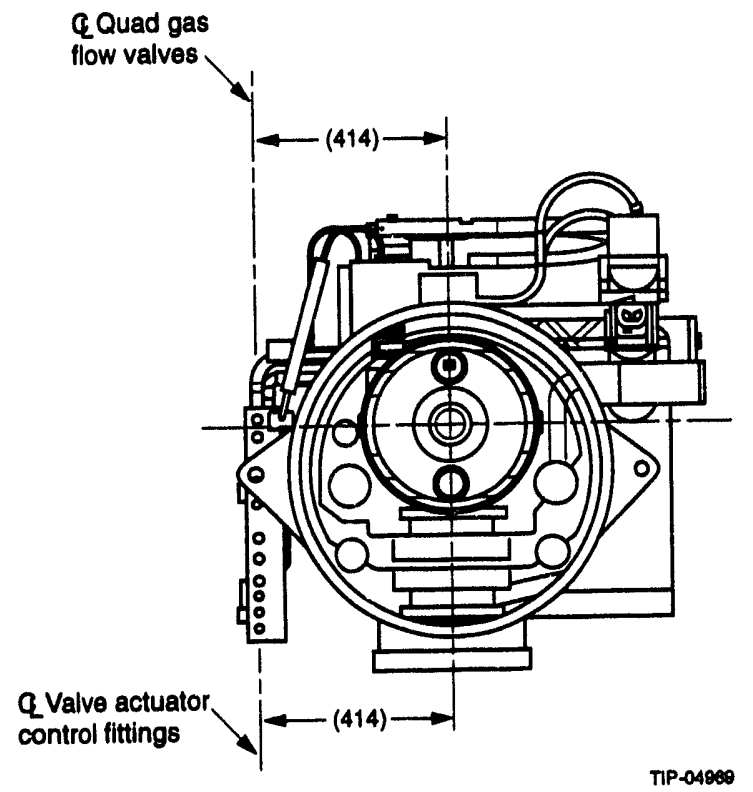

Figure 14. Cross section of the SPXA interconnect. The collider aisle is to the right. Dimensions are in millimeters. 


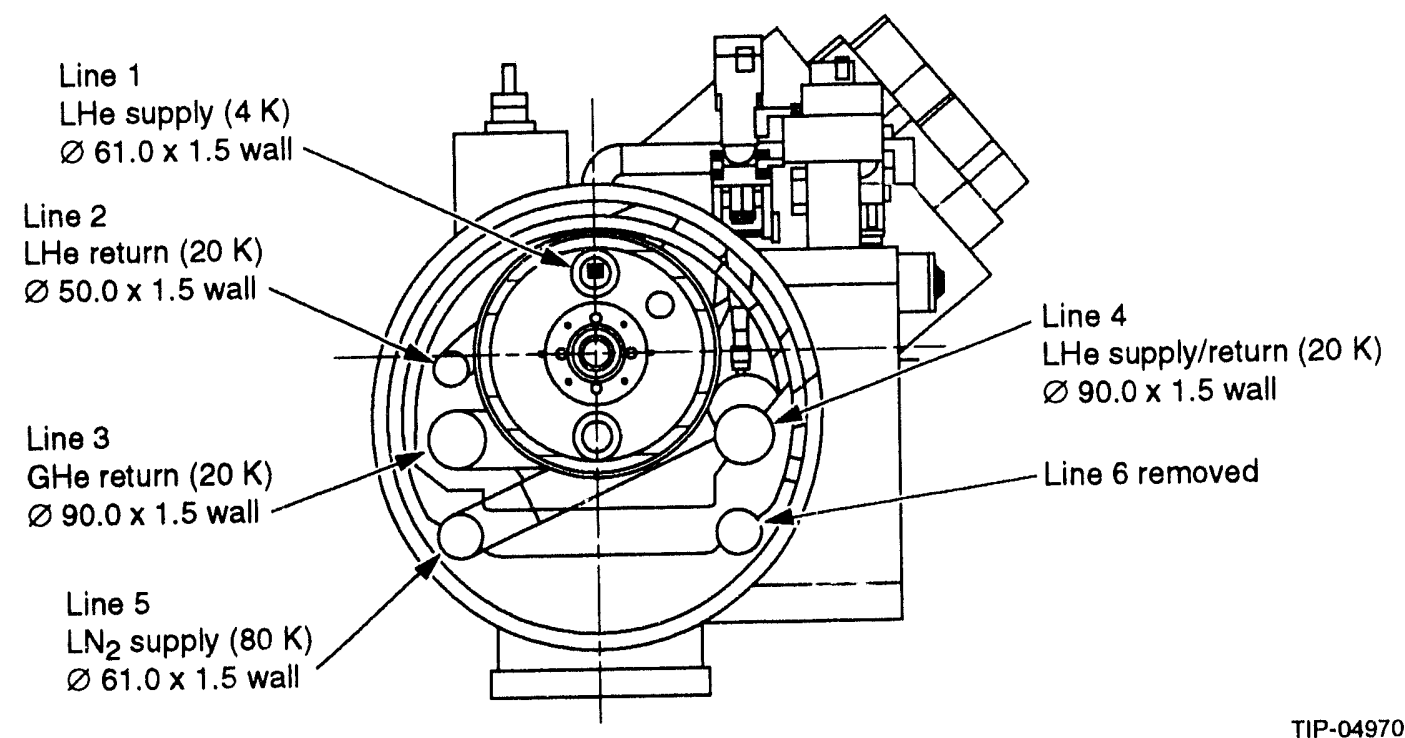

Figure 15. Cross section of the SPRT-L spool piece. The collider aisle is to the right.

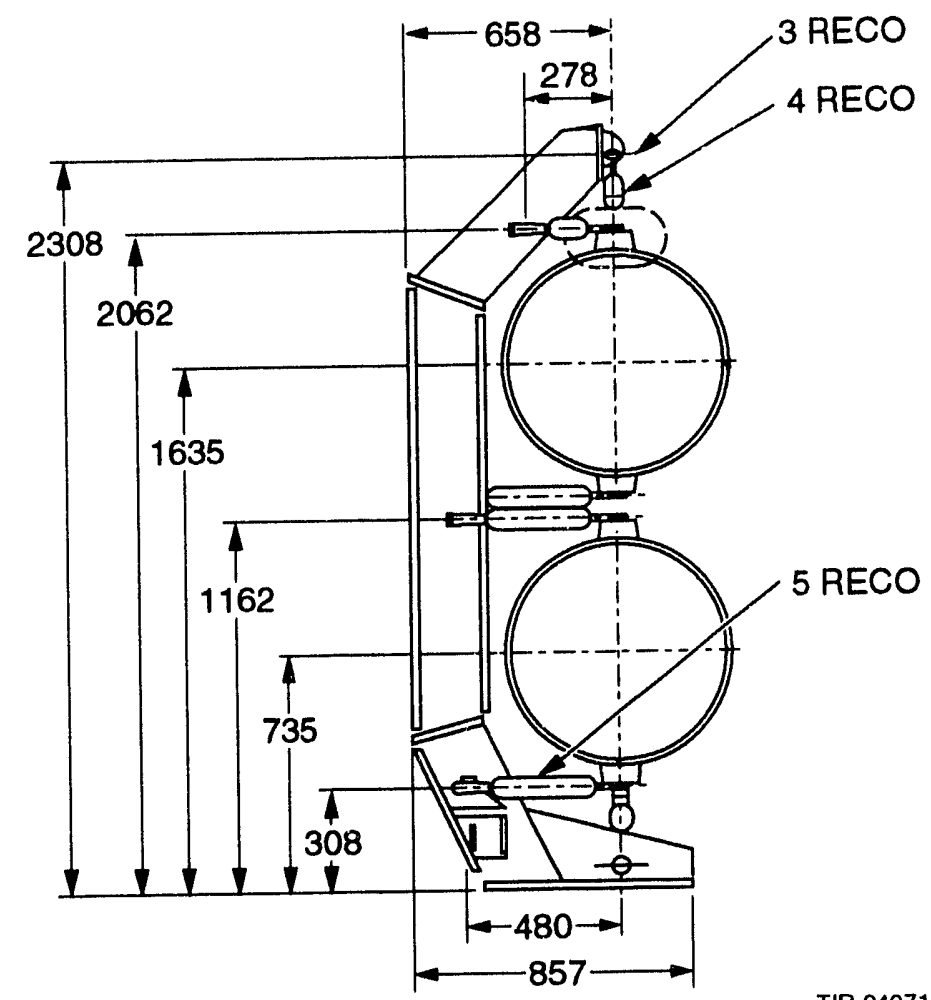

Figure 16. Cross section of a magnet support. Dimensions are in millimeters. 


\subsection{TRANSPORTING THE BEAM TO THE ALCOVE}

A trim magnet (ED1) is needed for fine-pointing the beam to the alcove. There is about $30 \mathrm{~m}$ of free space between the last collimator and the magnet string at the end of the dogleg (see Figure 5). The ED1 magnet string is placed in this location (centered at $937.8 \mathrm{~m}$ from the start of the east utility straight). A bend of $0.308 \mathrm{mrad}$ is needed to get the beam to the proper position at the start of the alcove. This would require a field of 20.54 T.m or five standard TUD dipoles with a $17.5-\mathrm{m}$ slot length. They fit comfortably in the allowed space.

The extracted beam at the bend center of ED1 is offset by $44.2 \mathrm{~cm}$. This gives enough clearance for the TUD magnets, as shown in Figure 17.

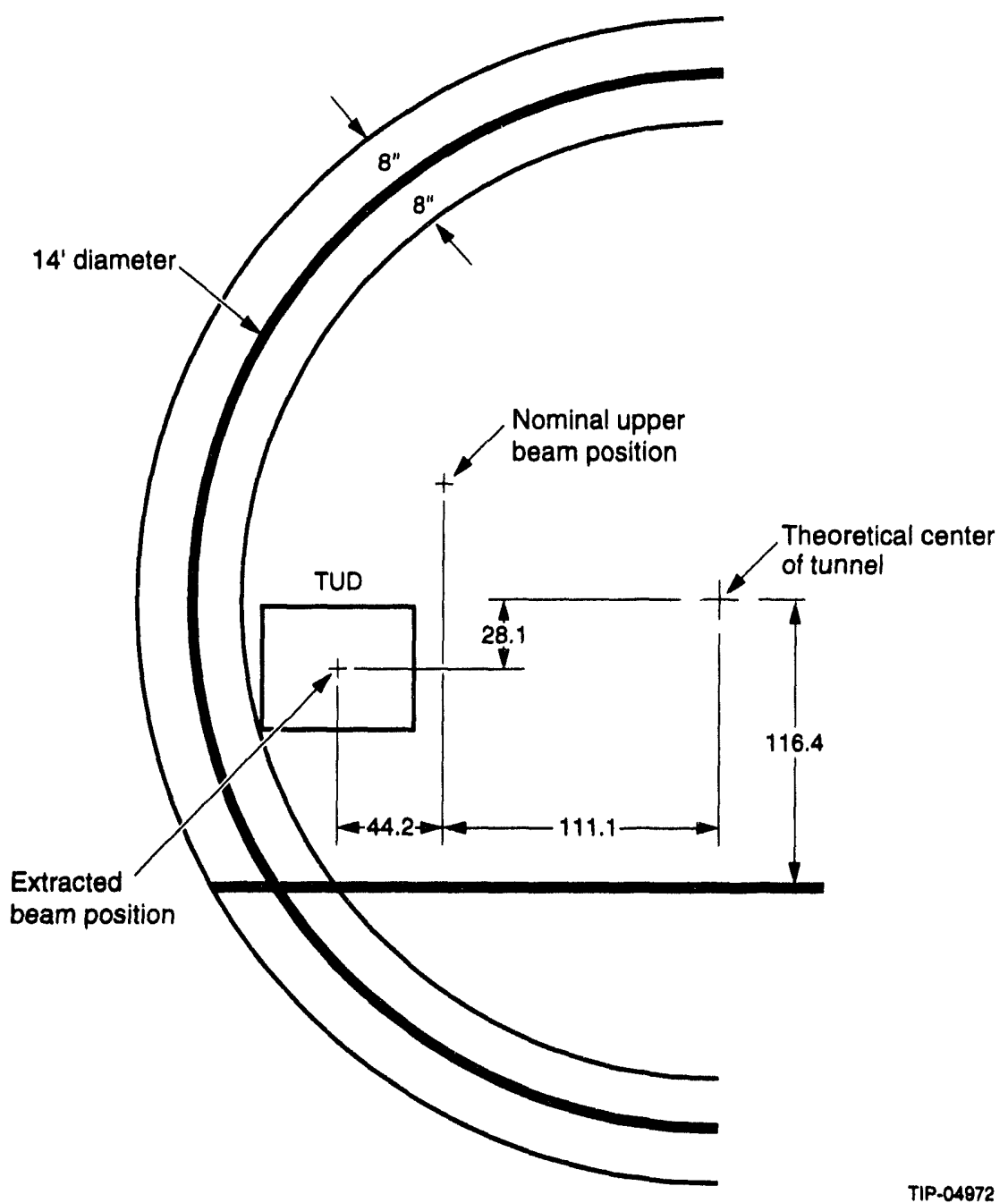

Figure 17. Cross section of the tunnel at the middle of the ED1 dipole string ( $837.8 \mathrm{~m}$ from the beginning of the east utility straight). All dimensions are in centimeters unless otherwise noted. 


\subsection{ALCOVE DESIGN}

The extracted beam encounters no empty cryostats between the QU2 and QU3 quadrupole magnets because of the warm pipe. At QU3 it misses the magnet supports by about $5 \mathrm{~cm}$, as shown in Figure 18. The alcove starts just after the QU4 quadrupole magnet at $1160 \mathrm{~m}$ from the start of the east utility straight and is $160 \mathrm{~m}$ in length. The alcove depth is $3 \mathrm{ft}$ for the first $120 \mathrm{~m}$ and $4 \mathrm{ft}$ for the remaining $40 \mathrm{~m}$. A detailed plan of the alcove is given in Figure 19. The position of the beam at the beginning of the alcove is shown in Figure 20.

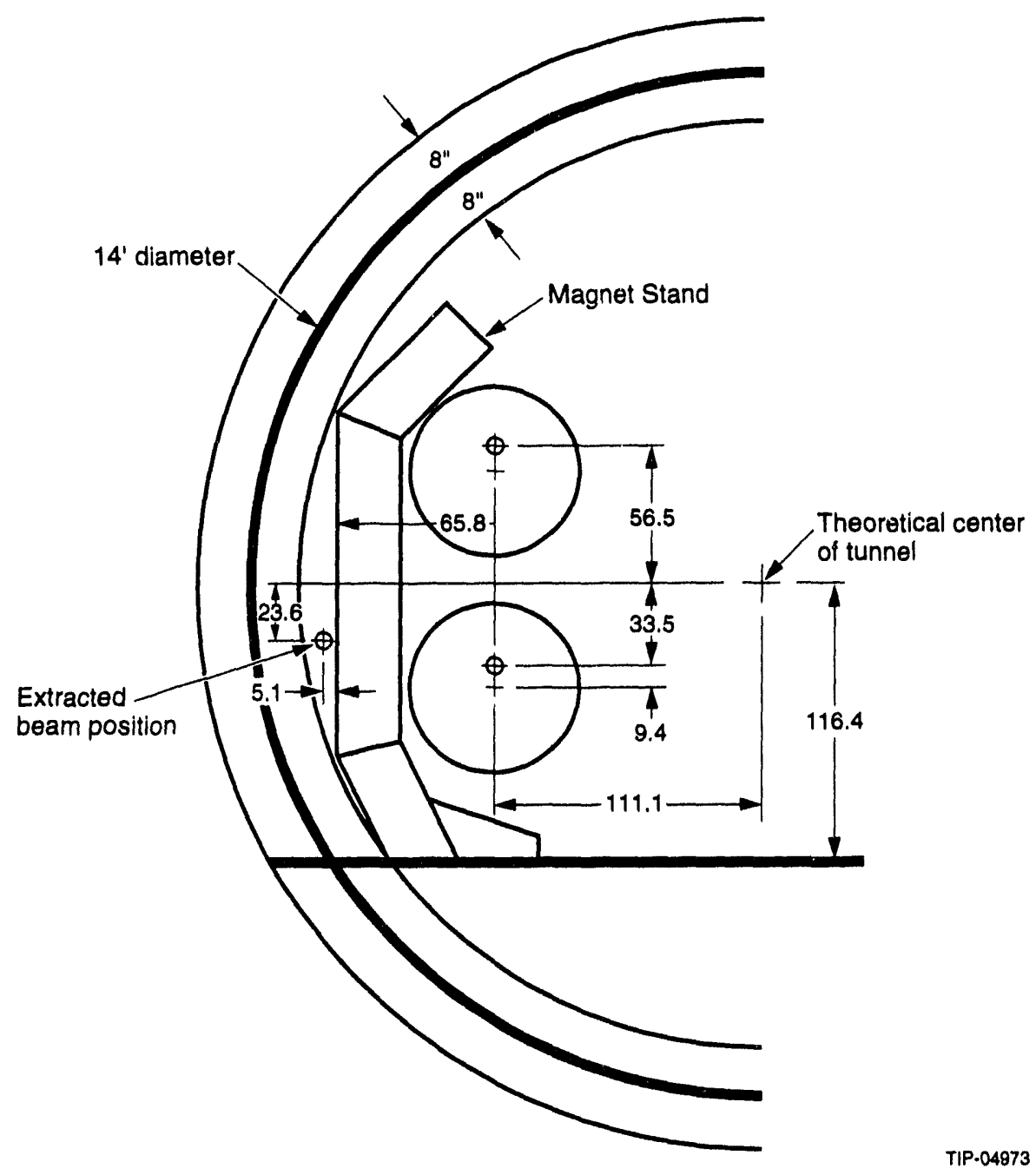

Figure 18. Position of the extracted beam at the QU3 magnet $(1116.11 \mathrm{~m}$ from the beginning of the east utility straight). All dimensions are in centimeters unless otherwise noted. 


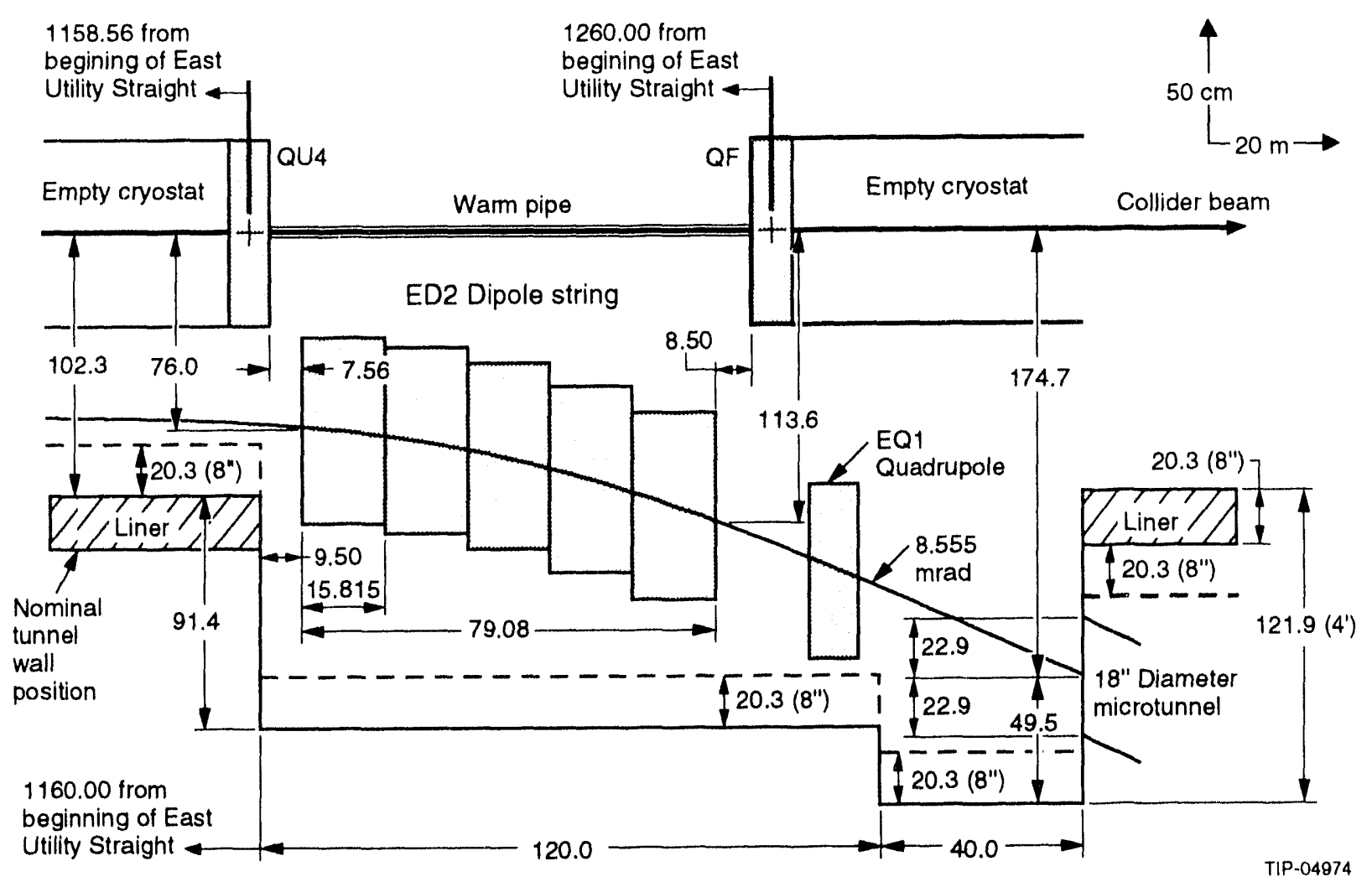

Figure 19. Plan view of the alcove. The dashed lines show the worst-case displacement of the tunnel walls relative to the theoretical tunnel center. Dimensions along the beam direction are in meters, whereas dimensions transverse to the beam direction are in centimeters.

The alcove has been positioned to begin just after the QU4 dipole and to end just before the end of the east utility straight. By situating the alcove at the end of the straight, advantage is taken of the sharp turn the circulating beam takes in the DS region, separating the extracted beam line tunnel and collider tunnel as rapidly as possible. This minimizes the length of microtunnel needed to transport the beam to the first shaft (which is required to be at least one shaft diameter from the collider tunnel).

A sharp bend is needed to get the beam deep enough into the alcove to allow a microtunnel to be bored. The bend (ED2) is done by five standard $15-\mathrm{m}$ collider dipoles. The ED2 string is situated between QU4 and QF, so the cryo and power from the lower ring can be used. Special spool pieces transferring the cryo and power need to be designed. Approximately $7.5 \mathrm{~m}$ between the end of QU4 and beginning of the ED2 magnet string, and $8 \mathrm{~m}$ between the end of the ED2 magnet string and the beginning of the QF quadrupole are available for these spool pieces. After the ED2 magnet string is a quadrupole magnet, EQ1, which is identical to QU1 (8.825-m slot length) and which allows the size of the beam at the experimental target to be controlled. 


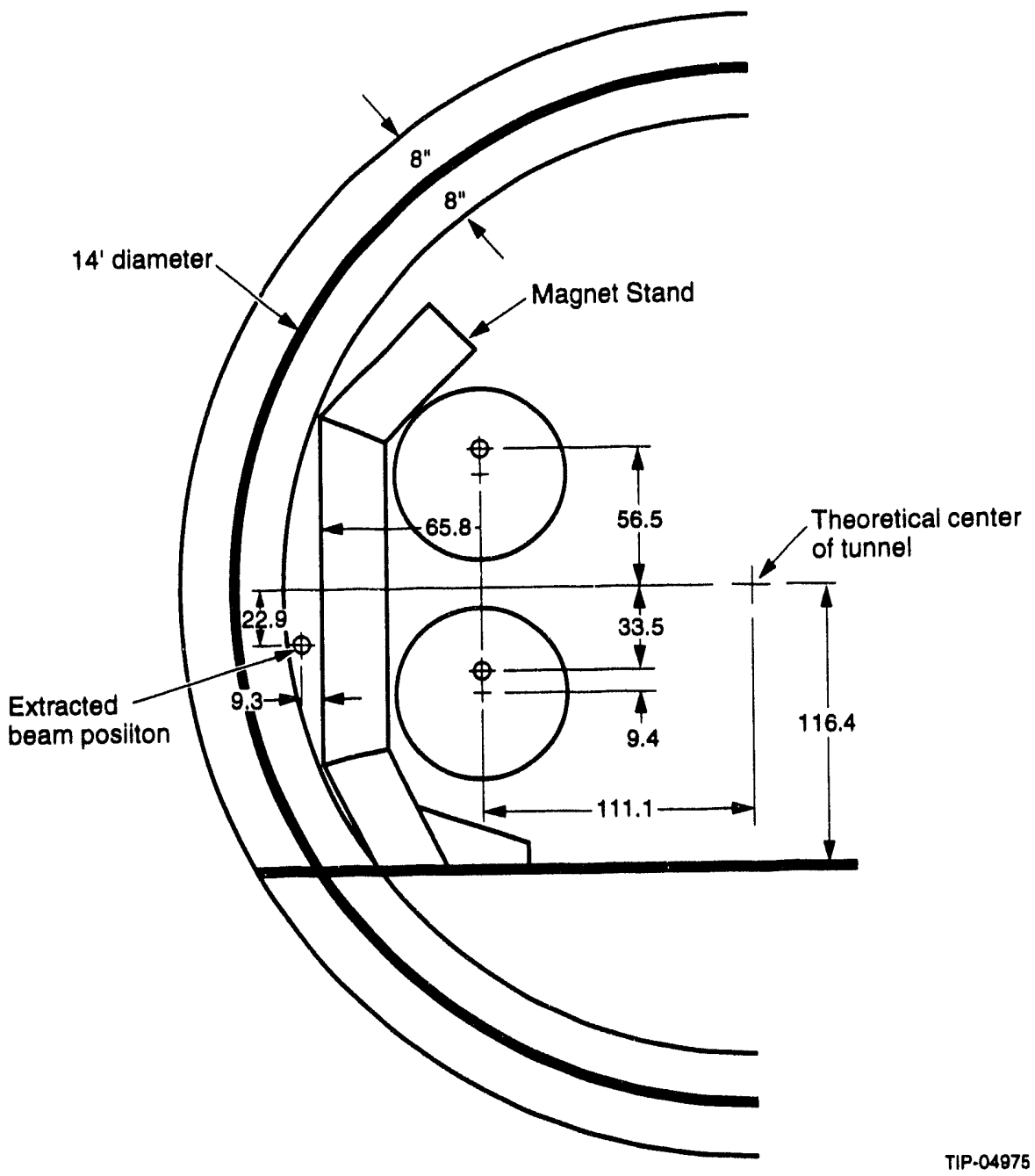

Figure 20. Position of the extracted beam at the beginning of the alcove $(1160.0 \mathrm{~m}$ from the beginning of the east utility straight). All dimensions are in centimeters unless otherwise noted.

The length and depth of the downstream 4-ft alcove has been chosen to assure that the 18-in.-diameter microtunnel fits at the alcove end (shown in Figure 21) given the \pm 8 -in. variation in the tunnel wall from the theoretical center and an 8-in.-thick tunnel liner. The 3-ft-deep alcove allows enough room for the magnets, as shown in Figure 22, giving the tunnel cross section at the end of the ED2 dipole string. 


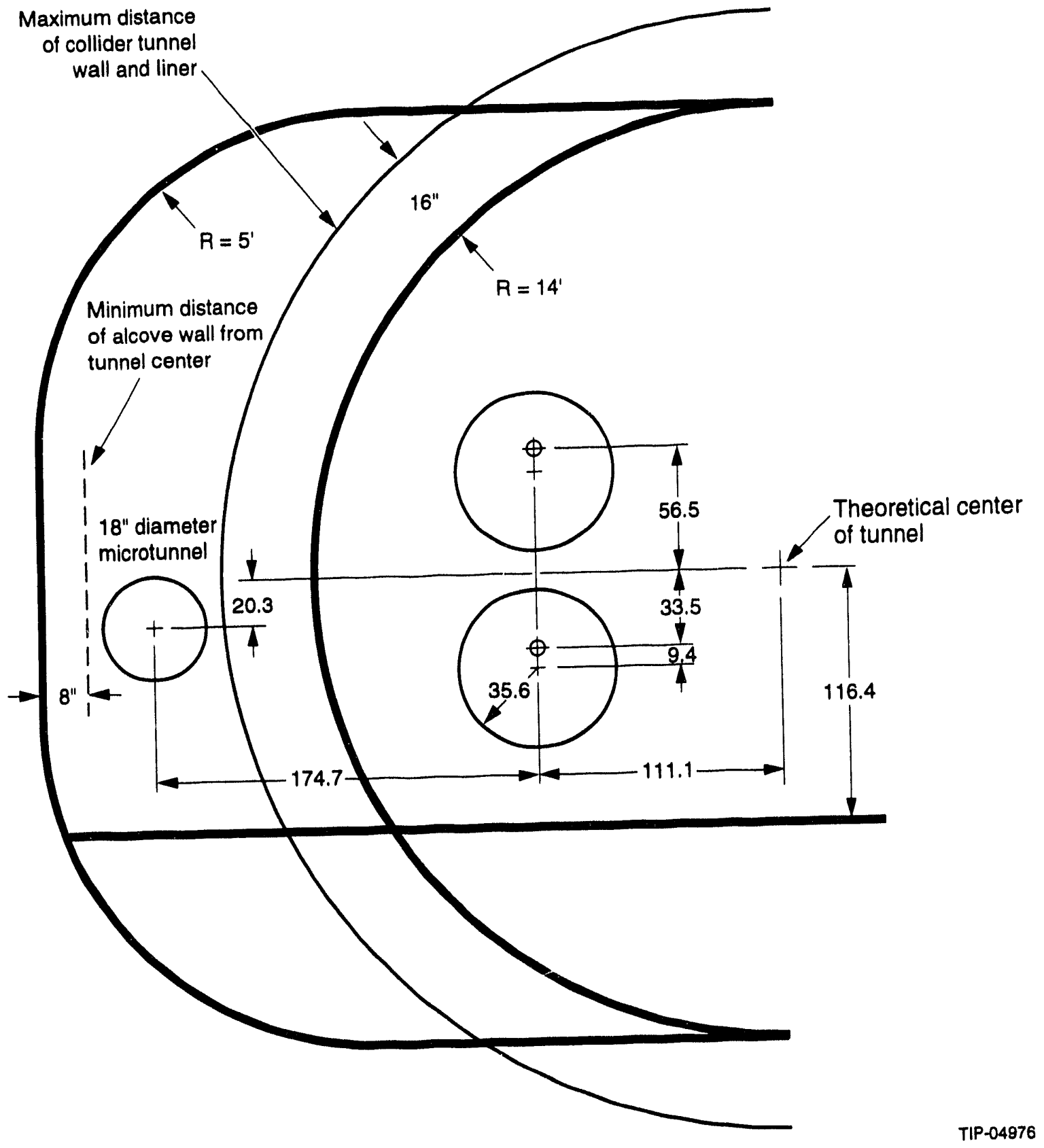

Figure 21. Cross section of the tunnel at the end of the alcove $(1320.0 \mathrm{~m}$ from the beginning of the east utility straight). All dimensions are in centimeters unless otherwise noted. 


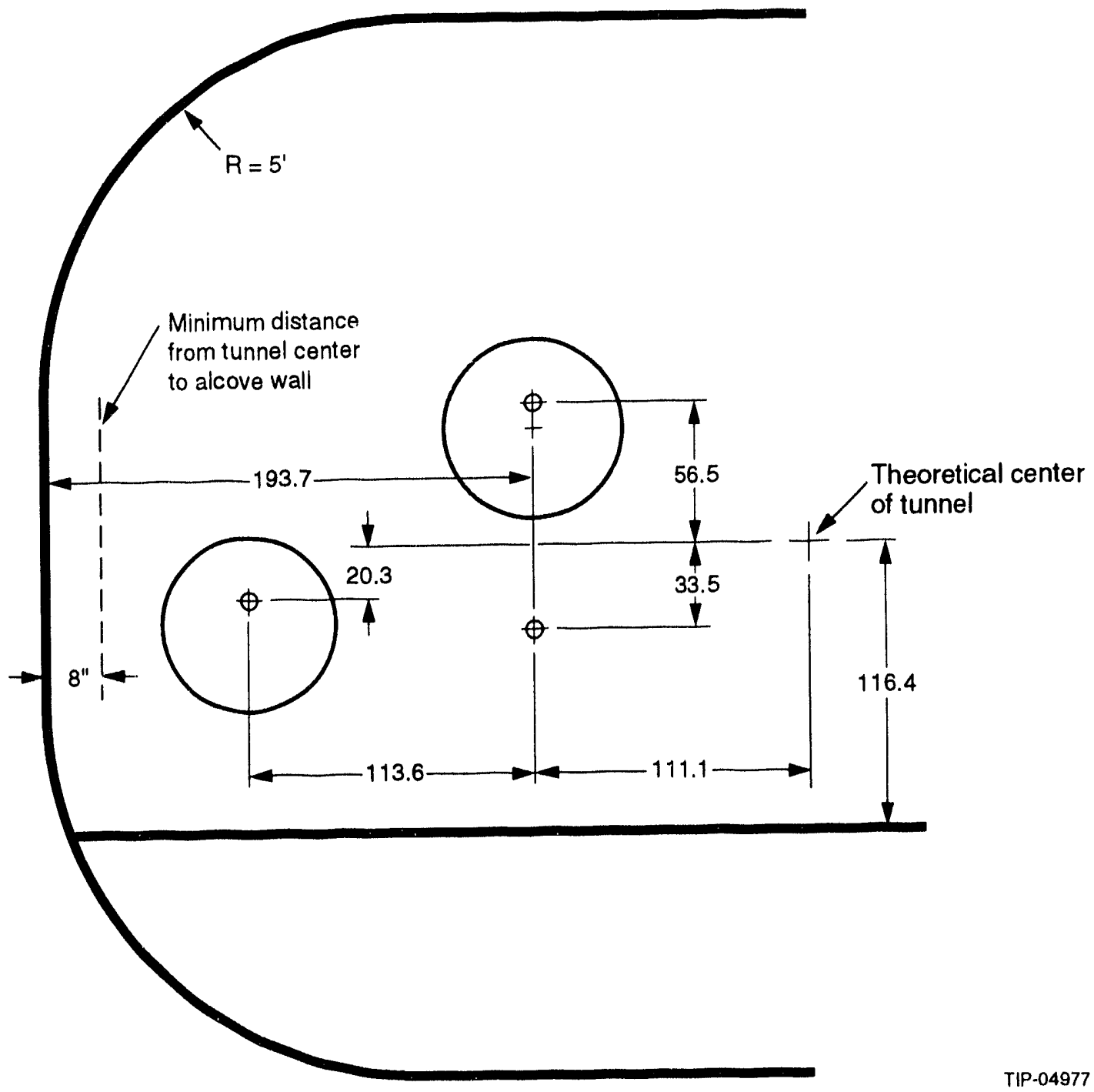

Figure 22. Cross section of the tunnel at the end of the ED2 dipole string (1248.6 $\mathrm{m}$ from the beginning of the east utility straight). All dimensions are in centimeters unless otherwise noted.

\subsection{THE EXTRACTED BEAM TUNNEL}

The use of microtunnels allows a modest-sized alcove to be used to mate the collider tunnel with the extracted beam line. The minimum-sized microtunnel that can be bored for a reasonable distance is approximately $18 \mathrm{in.} \mathrm{in} \mathrm{diameter.} \mathrm{This} \mathrm{size} \mathrm{microtunnel} \mathrm{would}$ be $150 \mathrm{~m}$ in length and would be followed by a microtunnel of 48 -in. diameter and $200-\mathrm{m}$ length. (An 18-in.-diameter tunnel cannot be bored for the full $350-\mathrm{m}$ length without the possibility of large deviations from the nominal line.) After $350 \mathrm{~m}$ the beam line is far enough away (approximately $8 \mathrm{~m}$ ) from the collider tunnel to allow a small hall to be excavated without affecting the integrity of the collider tunnel. The hall would be 
$15 \mathrm{ft} \times 15 \mathrm{ft} \times 40 \mathrm{ft}$, adequate size for the tunneling machine and associated machinery. ${ }^{13}$ A shaft to the surface would be at this hall.

The 48-in. tunnel would be drilled first from the shaft end. A microtunnel of this diameter can be drilled for longer distances than an 18-in. tunnel because the large diameter allows access for surveying. After $200 \mathrm{~m}$ the machine would have to be cut up and removed. The 18-in. tunnel would be drilled after the 48-in. tunnel and would start from the alcove. There is sufficient space for the jig needed to drill the tunnel. A length of $150 \mathrm{~m}$ is about the maximum allowable with an 18-in. diameter microtunnel. The boring machine would be removed via the 48 -in. tunnel.

The microtunnels would be lined with 20 -ft segments of flush-threaded pipe. The beam pipe would be installed in a manner similar to that envisaged for the Medium Energy Booster test beam.

The position of the experimental hall shown in Figure 2 is essentially the same as that proposed by Murphy and Stefanski in Reference 14. The beam line would be microtunnel, with occasional shafts for access to trim magnets, pumps, and other equipment. Detailed design of the beam line has yet to be worked out. In order to avoid the muon vectors coming from IR5 (GEM) and IR8 (SDC), the experimental hall is located $2000 \mathrm{~m}$ from the end of the east utility straight. At this point the hall is about $560 \mathrm{ft}$ from the collider tunnel, well within the fee-simple land acquired for the SSC. There is no water above the experimental hall preventing a shaft from reaching the surface.

\subsection{COST ESTIMATE}

A preliminary cost estimate has been performed by Gunter Matthes of PB/MK. ${ }^{15}$ This estimate includes overhead and design and construction management fees. The cost, itemized in Table 1, includes the cost of demolishing the liner. Removing a portion of the floor (invert), should the alcove be excavated after its addition, would not increase the cost. This estimate is very conservative and undoubtedly overstates the true cost. Matthes' estimate of the time needed to complete the excavation of the alcove is 4 months. Note that the tunnel is in Taylor Marl, which greatly adds to the alcove cost.

A preliminary estimate of the cost for the microtunnel and shaft (with a $40 \mathrm{ft} \times 15 \mathrm{ft} \times 15 \mathrm{ft}$ chamber) was also made by Matthes. It is given in Table 2. As with the alcove excavation, this estimate is very conservative, and the true cost will probably be lower. In particular, the estimates of the microtunnel costs are little better than a rough guess at $\$ 775$ and $\$ 550$ per linear foot, respectively, for 48 -in.- and 24 -in.-diameter tunnels. (No estimate for an 18-in.-diameter tunnel was possible.) These should be compared to the costs of $\$ 1000$ and $\$ 600$ per linear foot, respectively, for the lined and unlined collider tunnels! 
The time needed to excavate the shaft, chamber, and microtunnel is estimated to be 3,1 , and 2.5 months, respectively.

These estimates assume that the alcove would be excavated before the tunnel is finished-that is, after only the liner and perhaps floor have been added to the excavated tunnel. Excavating the alcove after the tunnel is finished would be far more expensive and could disrupt the collider construction timetable. At this time it is not known when the east utility straight tunnel will be finished.

We have no cost estimate for the tunnel to the experimental area or the experimental hall itself. Nor have we made estimates of the cost of the magnetic elements, as it is impossible at this time to get reliable figures.

Table 1. Estimated Alcove Cost.

\begin{tabular}{|l|c|c|c|}
\hline & Amount & Unit Cost & Total Cost \\
\hline Excavation & $1400 \mathrm{yd}^{3}$ & $\$ 200 / \mathrm{yd}^{3}$ & $\$ 280000$ \\
Demolition & $340 \mathrm{yd}^{3}$ & $\$ 350 / \mathrm{yd}^{3}$ & $\$ 120000$ \\
Shotcrete & $630 \mathrm{yd}^{3}$ & $\$ 500 / \mathrm{yd}^{3}$ & $\$ 315000$ \\
Dowels & 1315 & $\$ 50$ each & $\$ 65000$ \\
Lattice girders & $41600 \mathrm{lb}$ & $\$ 5 / \mathrm{lb}$ & $\$ 210000$ \\
Invert concrete & $235 \mathrm{yd}^{3}$ & $\$ 250 / \mathrm{yd}^{3}$ & $\$ 60000$ \\
Total & & & $\$ 1050000$ \\
\hline
\end{tabular}

Table 2. Estimated Microtunnel, Chamber, and Shaft Costs.

\begin{tabular}{|l|r|r|r|}
\hline & Amount & Unit Cost & Total Cost \\
\hline Chamber & & & \\
Excavation & $375 \mathrm{yd}^{3}$ & $\$ 150 / \mathrm{yd}^{3}$ & $\$ 56250$ \\
Shotcrete & $75 \mathrm{yd}^{3}$ & $\$ 400 / \mathrm{yd}^{3}$ & $\$ 30000$ \\
Dowels & $150 \mathrm{yd}^{3}$ & $\$ 50$ each & $\$ 7500$ \\
Invert concrete & $35 \mathrm{yd}^{3}$ & $\$ 250 / \mathrm{yd}^{3}$ & $\$ 8750$ \\
Subtotal & & & $\$ 102000$ \\
\hline Access Shaft $(160 \mathrm{ft}, 15-\mathrm{ft}$ diameter $)$ & & & $\$ 750000$ \\
\hline Microtunnels & & & \\
24 -in. diameter & $492 \mathrm{ft}$ & $\$ 550 / \mathrm{lft}$ & $\$ 270000$ \\
48 -in. diameter & $656 \mathrm{ft}$ & $\$ 775 / \mathrm{lft}$ & $\$ 510000$ \\
Subtotal & & & $\$ 780000$ \\
\hline Total & & & $\$ 1632000$ \\
\hline
\end{tabular}




\section{ACKNOWLEDGEMENTS}

The authors would like to thank N. Mokhov, J. Shively, R. Smellie, and T. Toohig for suggestions and discussions. 


\section{REFERENCES}

1. C.H. Sun et al., "Slow Parasitic Extraction at the SSC Using Crystal Septa," Proc. 1984 Summer Study on the Design and Utilization of the SSC, Snowmass (1984) p. 483. B. Cox et al., "The Possibility of Parasitic $20 \mathrm{TeV}$ Beams Extracted from the SSC Using Bent Crystals," Proc. 1988 Summer Study on the Design and Utilization of the SSC, Snowmass (1988) p. 536.

2. The SFT Collaboration, An Expression of Interest in a Super Fixed Target Beauty Facility at the SSC, EOI-14, submitted to the SSC PAC, 25 May 1990.

3. L. Coulson, R. Crawley, H. Edwards, D. Getz, M. Gilchriese, R. Schwitters, P. Shelley, R. Stefanski, and T. Toohig, "Footprint Characterization Document," SSCL-SR-1041 (Rev. 1), June 1992.

4. A.F. Elishnev et al., Phys. Lett. B88 (1979) 387. V. Samsonov, Relativistic Channeling, eds. R.A. Carrigan Jr. and J.A. Ellison, Plenum, New York, 1987, p. 129. S.I. Baker et al., Nucl. Instr. Meth. A248 (1986) 301. A.A. Asseev et al., Nucl. Instr. Meth. A309 (1991) 1. S.P. Moller et al., Phys. Lett. B256 (1991) 91.

5. D. Chen et al., "First Observation of Magnetic Moment Precession of Channeled Particles in Bent Crystals," FERMILAB-Pub-92/242, September 1992.

6. O.D. Barr et al., "Proposal for a Precision Measurement of $\epsilon^{\prime} / \epsilon$ in CP Violating $K^{\circ} \rightarrow 2 \pi$ Decays," CERN/SPSC/90-22, 20 July 1990.

7. The RD22 Collaboration, "Status Report on RD22: Crystal Extraction at the SPS," CERN/DRDC 92-51, 26 October 1992.

8. G. Carboni, private communication.

9. The E853 Collaboration, "Proposal for a Test of Low Intensity Extraction from the Tevatron Using Channeling in a Bent Crystal," Fermilab Proposal E853, May 1991.

10. "Collider Accelerator Utility Sections," Specification No. E10-000073, Issue Date: 3/8/93, Revision: Draft E.

11. "Collider Preliminary Design Requirements Review (PDRR)," photocopies of the PDRR meeting of 27-28 January, 1993.

12. Rae Steining, private communication.

13. John Shively, private communication.

14. C.T. Murphy and R. Stefanski, "Modification to Footprint to Accommodate an External Fixed-Target Hall," SSCL-428, September 1989.

15. Gunter Matthes, private communication. 

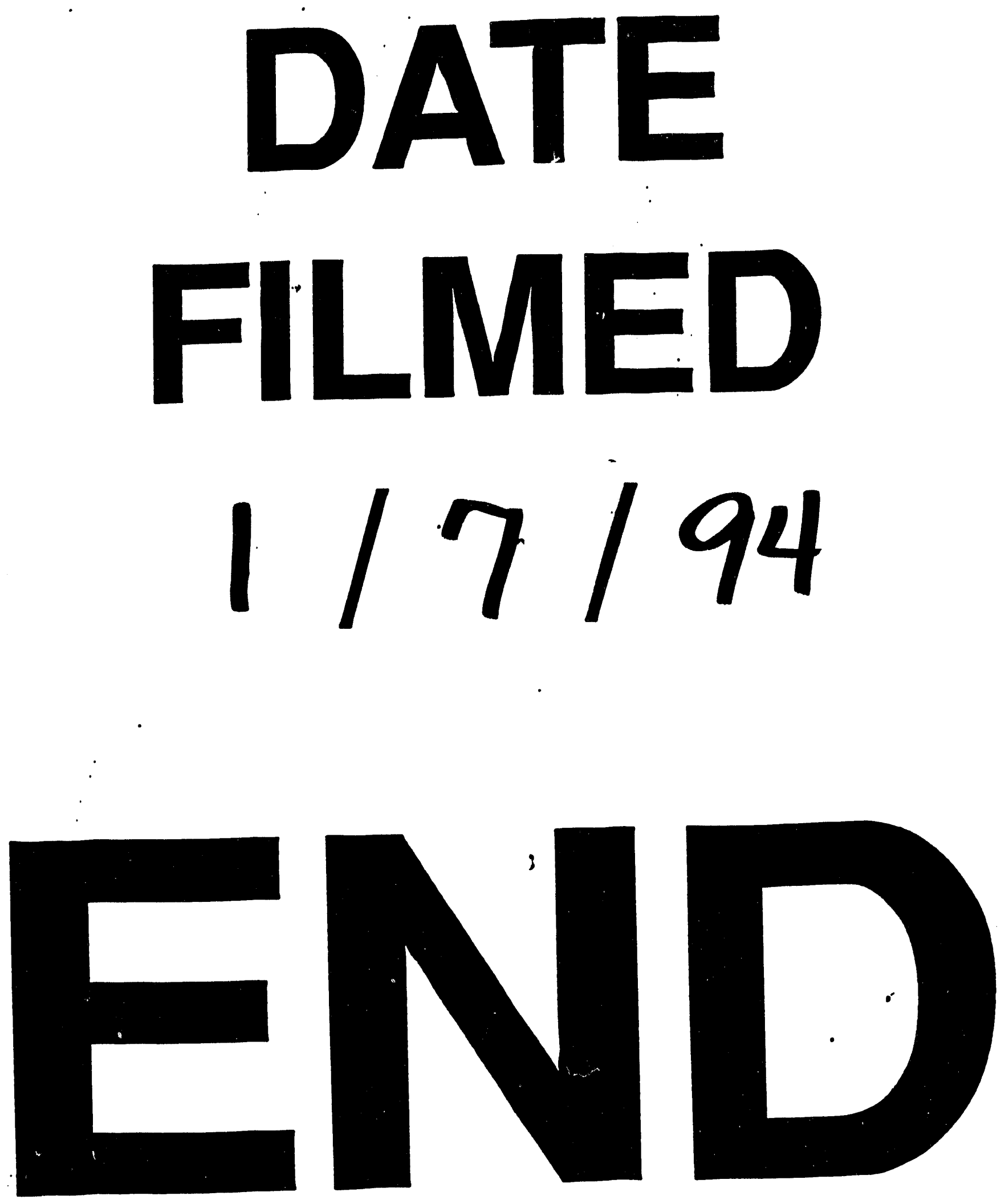
